\title{
Use of the nicotine skin patch by smokers in 20 communities in the United States, 1992-1993
}

Department of Cancer Control and Epidemiology, Roswell Park Cancer Institute, Buffalo, New York, USA

K M Cummings

A Hyland

Division of Preventive and Behavioral

Medicine, University

of Massachusetts

Medical School,

Worcester,

Massachusetts

J K Ockene

Department of Psychiatry, University of Medicine and Dentistry of New Jersey, Newark, New Jersey

N Hymowitz

Public Health

Applications Research Branch, National Cancer Institute, Rockville, Maryland

M Manley

Correspondence to: Dr K Michael Cummings, Department of Cancer Control and Epidemiology, Roswell Park Cancer

Institute, Elm and Cariton Streets, Buffalo, New York 14263, USA; email: mcummings@sc3102.med. buffalo.edu

\author{
K Michael Cummings, Andrew Hyland, Judith K Ockene, Norman Hymowitz, \\ Marc Manley
}

\begin{abstract}
Objective-To measure the characteristics of smokers associated with the use of the nicotine skin patch in the general population and to evaluate whether use of the patch is associated with successful smoking cessation.

Design-Data from two surveys conducted in 20 communities in the United States as part of the National Cancer Institute's Community Intervention Trial for Smoking Cessation (COMMIT) study. Nicotine patch prevalence was estimated using data from a 1993 cross-sectional survey of 13691 current and former smokers. The effectiveness of the nicotine skin patch as a smoking cessation aid was evaluated adjusting for other covariants using data from a cohort tracking study of 9809 smokers who were followed between 1988 and 1993. As the nicotine patch was not available to consumers until January 1992, analyses were restricted to respondents who reported themselves to be current smokers in 1993 or former smokers who reported quitting after January 1992.
\end{abstract}

Outcome measures-Current and former smokers who reported having made a serious effort to stop smoking in the past five years were asked to indicate whether they had used the nicotine skin patch to help them stop smoking. Those answering "Yes", were classified as nicotine patch users. Smoking cessation was based on self-report. A "quitter" was defined as someone who had been a smoker as of January 1992 who reported in 1993 not smoking any cigarettes for the preceding six months or longer.

Results-The prevalence of nicotine patch use by smokers averaged across the 20 study communities was $12.8 \%$, making the patch one of the most popular cessation methods used by smokers. Compared with non-users, patch users were more likely to be female, white, have higher annual household incomes, be more motivated to stop smoking, and to smoke more heavily. Among low-income smokers (annual household income below US\$10 000), nicotine patch use was significantly higher among those who lived in a state where the public insurance programme (Medicaid or Medi-Cal) included the patch as a benefit $(12.1 \%$ vs $7.7 \%)$. Among those who made an attempt to quit smoking, the likelihood of successful quitting was more than twice as high among patch users compared with non-users. Among patch users, the highest quit rates were observed among those who used the patch for between one and three months.

Conclusions-The nicotine skin patch is a popular and effective means of smoking cessation. Use of the nicotine patch, especially by low-income smokers, could be increased by reducing the out-of-pocket expenditure required for smokers to get the product.

(Tobacco Control 1997;6 (suppl 2):S63-S70)

Keywords: nicotine skin patch; smoking cessation

\section{Introduction}

Smoking cessation ranks among the most cost effective of preventive medical interventions. ${ }^{1-3}$ Despite this fact, most health insurance carriers do not provide coverage for nicotine addiction. ${ }^{4-7}$ One explanation for this anomaly is that the benefits from smoking cessation are abstract and deferred, whereas the costs are tangible and immediate. Smoking cessation treatments are also fairly inexpensive. As such, insurance carriers may not feel the need to cover services that most smokers could probably afford on their own. ${ }^{8}$

One argument for reimbursing smoking cessation services is that it would promote efforts by smokers to quit. This argument rests on the assumption that lack of reimbursement for such services is a barrier to quitting. This assumption, while reasonable, is untested.

In December 1991, the United States Food and Drug Administration (FDA) approved the marketing of prescription nicotine transdermal patches to help treat tobacco dependence. Clinical trials have demonstrated that the nicotine patch is an effective aid for helping smokers quit with cessation rates often twice as high among active compared with placebo patch users. $^{39-11}$ The introduction of the patch was accompanied by an unprecedented direct marketing campaign by the pharmaceutical industry urging smokers to ask their physicians about "the patch". In 1992, the transdermal nicotine patch became the most widely prescribed drug in the United States. ${ }^{12}$

The out-of-pocket cost of a three-month supply of nicotine transdermal patches is approximately $\$ 300-\$ 350$. Despite evidence demonstrating its efficacy for promoting smoking cessation, not all health insurance carriers reimburse for the patch-for example, in 1992, only 23 states and the District of Columbia 
included the nicotine transdermal patch under their Medicaid pharmaceutical programmes.

At the time that the nicotine transdermal patch came onto the market in the United States, the Community Intervention Trial for Smoking Cessation (COMMIT) funded by the National Cancer Institute was already in progress and it involved tracking the smoking habits and cessation behaviour of representative samples of cigarette smokers in 20 American and two Canadian communities. ${ }^{13}$ Because COMMIT encompassed the period in which the nicotine transdermal patch was introduced into the market, it provided a unique opportunity to describe the use of this therapy in a large number of smokers and to determine whether factors such as income and insurance coverage affect use.

Despite the popularity of the transdermal nicotine patch as an aid for quitting smoking, only a handful of studies have examined the use of the patch among smokers in the general population. ${ }^{14-16}$ Pierce and colleagues ${ }^{14}$ examined use of the nicotine skin patch in over 3000 smokers responding to the 1993 California tobacco survey. Compared with non-users, patch users were more likely to be female, white or Asian, middle aged, and smokers of more cigarettes. Orleans and colleagues ${ }^{15}$ reported similar findings in a study of older smokers.

We used data from the COMMIT study to measure the prevalence of patch use in the general population during 1992, according to demographic and other subject characteristics. In addition, the extent to which income and public insurance coverage may have influenced use of the transdermal nicotine patch is examined. Finally, the smoking status of smokers who did and did not make use of the transdermal nicotine patch is compared.

\section{Methods}

DATA COLLECTION

The data came from a cross-sectional telephone survey of adults conducted in 1993 in the 20 American COMMIT communities: Bellingham and Longview/Kelso, Washington; Albany/Corvallis and Medford/Ashland, Oregon; Vallejo and Hayward, California; Santa Fe and Las Cruces, New Mexico; Cedar Rapids and Davenport, Iowa; Raleigh and Greensboro, North Carolina; Paterson and Trenton, New Jersey; Lowell and Fitchburg/Leominster, Massachusetts; and Yonkers, New Rochelle, Utica, and Binghamton/Johnson City, New York. The data from a cohort tracking survey of adult cigarette smokers in the same communities followed between 1988 and 1993 was also analysed.

Data from the cross-sectional survey are used to estimate overall the prevalence of patch use, and the use of other smoking cessation methods for current smokers and recent quitters in each of the 20 COMMIT communities and to determine characteristics of smokers related to use of the patch. Data from the cohort tracking survey are used to evaluate the relationship between use of the transdermal nicotine patch and smoking cessa- tion. Similar to the cross-sectional survey, it also provides data regarding characteristics of patch users.

Surveys were conducted under the auspices of the National Cancer Institute. All survey instruments and data collection procedures were reviewed and approved by an external scientific advisory committee appointed by the National Cancer Institute and by the Office of Management and Budget. In all surveys conducted as part of the COMMIT study, respondents were informed that their participation in the survey was voluntary and that they could refuse to answer questions or discontinue their participation at any time. Each of these surveys has been described in detail elsewhere and is summarised briefly detail elsewhere from the two Canadian communities in COMMIT were excluded communities in patch was not made available in Canada until late 1993.

\section{CROSS-SECTIONAL SURVEY}

The 1993 survey was the second of two population-based, cross-sectional surveys conducted as part of the COMMIT study to estimate cigarette smoking prevalence in the 20 American communities. The survey was conducted centrally between August 1993 and January 1994, using a modified, random-digit dialling technique with community-specific geographic screening to identify an average of 2300 households per community. Data were gathered in two stages. In the first stage, a screener interview was done with an adult in screener household to enumerate all adult household members and gather information about the demographic characteristics and smoking status of each. In the second stage, an adult in the household aged 25-64 years was selected to participate in a more detailed interview about his or her smoking status and history, beliefs, and attitudes about smoking, and, among current smokers and former smokers, methods used to stop smoking, including use of the transdermal nicotine patch.

\section{COHORT TRACKING SURVEY}

From January to May 1988 a telephone survey was conducted to identify cohorts of approximately 915 current cigarette smokers aged $25-64$ years in the communities. The sampling methods and procedures used for this survey were analogous to those used in the 1993 cross-sectional survey described above, although this baseline survey was larger, involving about 5400 households per community. In the screener interview stage of the survey, all those aged 18 years and older were rostered by an adult household member who provided information on their age, sex, and smoking status. In the second stage of the survey, a sample of current smokers aged 25-64 years was selected for an extended interview which included questions about current and past smoking habits, brand and type of cigarette usually smoked, interest in quitting smoking, and demographic characteristics. 
The initial cohort identification survey gathered data on a total of 18332 current smokers aged 25-64 years who were then followed prospectively until 1993. Between 1988 and 1992, cohort participants were contacted once per year either by telephone or mail to assess their current smoking status and residency. Between January and May 1993 cohort members were contacted again by telephone and asked to respond to a 20-minute interview which included questions about current smoking status, efforts made to stop smoking since 1988 , and methods used to quit smoking, including a question on the use of the transdermal nicotine patch.

RESPONSE RATES TO THE SURVEYS

The mean response rate for the household The mean response for the cross-sectional survey was $72.3 \%$. The response rate for the extended interview portion of the survey was $80.2 \%$. Overall, data from the extended interview were collected on 23528 individuals, of whom 11783 were current smokers, 8823 were former smokers, and 2902 were wever-smokers. Information on the use of the transdermal nicotine patch was collected only on current adult smokers $(n=11783)$ and former smokers who reported having quit since January $1992(n=1908)$. Overall, $65.3 \%$ of cohort members of the cohort tracking survey $(n=11966)$ provided information on their smoking status at the final contact in 1993. Non-responders tended to be younger, single, and have fewer years of formal education compared with those who responded to the 1993 follow-up survey. As the focus of this analysis is on the use of the transdermal nicotine patch, and as the patch did not become available to consumers until after 1 January 1992, we have limited our analysis to the 9809 cohort members who reported themselves to be current smokers as of 1 January 1992 and who made at least one attempt to stop smoking between 1992 and the time of the follow-up interview in 1993.

\section{MEASUREMENT OF STUDY VARIABLES}

Smoking status

Smoking status was defined using standard questions about current smoking and lifetime smoking of at least 100 cigarettes. Former smokers were asked to provide a date when they last smoked regularly. Only former smokers who reported having stopped smoking after December 1991 were included in the analysis. In the cohort tracking study group, a "quitter" was defined as a smoker who, at the final annual contact in 1993, reported not smoking any cigarettes for the preceding six months or longer.

Use of the transdermal nicotine patch

In both the cross-sectional survey and the cohort survey former smokers and current smokers who reported having made a serious effort to stop smoking were asked to indicate whether they had used the transdermal nicotine patch to help them stop smoking. If they answered "Yes", the interview followed up with the question: "Over the past two years, for how many days did you wear the patch?" Information on the brand and dosage of the patch used was not obtained.

Use of other smoking cessation aids

In the cross-sectional survey and the cohort survey, former and current smokers were asked to report on their use of other smoking cessation aids (in addition to the nicotine patch) in the five years preceding the interview. These aids included use of nicotine gum, attendance at a smoking cessation programme, consultation from a psychiatrist or psychologist, hypnosis or acupuncture, the use of a selfhelp guide or booklet, and use of other commercial devices such as special filters.

\section{Smoker characteristics}

The relationship of the following sociodemographic characteristics to use of the transdermal nicotine patch and smoking cessation was assessed using the cross-sectional and cohort data.

- Gender

- Age (25-34, 34-44, 45-54, 55-64 years)

- Race/ethnicity (white, black, Hispanic, Asian, American Indian, other)

- Average annual household income $(<\$ 10000, \quad \$ 10000-\$ 25000, \quad \$ 25001-$ $\$ 40000,>\$ 40000)$

- Number of years of formal education $(<12$, $12,13-15,>15$ years)

- Employment status (retired, unemployed, employed, homemaker, student).

Among cohort members the following measures of past and current tobacco use behaviours were examined as predictors of patch use and smoking cessation.

- Age began smoking $(<16,16-19,>19$ years $)$

- Cigarettes smoked daily $(<5,5-14,15-24$, $>25$ )

- Time to first cigarette in the morning $(<10$, 10-30, 31-60, >60 minutes)

- Type of cigarette consumed (premium, discount, or generic brand)

- Use of non-cigarette tobacco products (none $v s$ either pipe tobacco, cigars, cigarillos, smokeless tobaccos)

- Number of quit attempts in the past year (none, one, two or more)

- Desire to stop smoking (none, a little, somewhat, a lot).

Public insurance coverage for the nicotine patch

Health insurance coverage for the nicotine patch was not measured in this study. However, household income below $\$ 10000$ was used as a proxy measure to identify respondents who were likely either to be uninsured or eligible for public health insurance. Public insurance coverage for the nicotine patch (Yes/No) was assigned for each respondent based on whether or not he/she lived in a state that included coverage for the patch. Information on public health insurance coverage (Medicaid and Medi-Cal) for the nicotine skin patch was obtained by contacting state health insurance offices in the states with COMMIT communities. 
Table 1 Use of different smoking cessation methods by current and former smokers from the 1993 cross-sectional survey

\begin{tabular}{lccc}
\hline Method & $\begin{array}{l}\text { Smokers } \\
(\%)\end{array}$ & $\begin{array}{l}\text { Quitters } \\
(\%)\end{array}$ & $\begin{array}{l}\text { Total } \\
(\text { (I) })\end{array}$ \\
\hline Nicotine patch & 11.9 & 18.6 & 12.8 \\
Nicotine gum & 9.9 & 8.7 & 9.6 \\
Attend smoking cessation programme & 8.2 & 9.5 & 8.4 \\
Decrease consumption & 47.9 & 36.5 & 45.0 \\
Switch to low tar cigarettes & 32.7 & 22.2 & 30.0 \\
Quit "cold turkey" & 59.6 & 90.5 & 67.6 \\
Go to a doctor for help & 14.6 & 13.5 & 14.3 \\
Hypnosis or acupuncture & 6.0 & 6.3 & 6.1 \\
Consult psychiatrist or psychologist & 1.4 & 0.9 & 1.3 \\
Use self-help booklet & 17.6 & 15.0 & 16.9 \\
Use other devices & 5.1 & 2.4 & 4.7 \\
\hline
\end{tabular}

The question allowed for multiple responses, therefore, percentages will not add up to 100 .

ANALYSIS METHODS

Prevalence estimates for each smoking cessation method were weighted to reflect variations in community-specific sampling fractions and response rates to the 1993 cross-sectional survey.

To evaluate characteristics of smokers associated with the use of the nicotine skin patch, weighted percentages of patch use were obtained from the cross-sectional survey for each of the following variables: gender, age, race/ethnicity, income, education, and employment status. In addition, a logistic regression analysis was performed modelling use of the patch (Yes/No) with the variables above entered into the model along with an indicator variable used to control for any COMMIT intervention effect. A similar analysis was performed using the data from the cohort tracking survey. Patch-use percentages were calculated for each of the variables analysed in the cross-sectional survey plus the additional independent variables assessed in the baseline cohort survey conducted in 1988. A logistic

Table 2 Characteristics associated with use of the nicotine skin patch from the 1993 cross-sectional survey

\begin{tabular}{|c|c|c|c|c|}
\hline \multirow[b]{2}{*}{ Characteristic } & \multicolumn{2}{|c|}{ Sample size } & \multirow{2}{*}{$\begin{array}{l}\text { Risk } \\
\text { estimate }\end{array}$} & \multirow[b]{2}{*}{$95 \% C I$} \\
\hline & $n$ & $\%$ & & \\
\hline \multicolumn{5}{|l|}{ Gender } \\
\hline $\begin{array}{l}\text { Male } \\
\text { Female }\end{array}$ & $\begin{array}{l}6639 \\
6886\end{array}$ & $\begin{array}{l}11.3 \\
14.3\end{array}$ & $\begin{array}{l}\text { Referent } \\
1.43\end{array}$ & $1.28-1.60$ \\
\hline \multicolumn{5}{|l|}{$\begin{array}{c}\text { Female } \\
\text { Age (years) }\end{array}$} \\
\hline $\begin{array}{l}25-34 \\
35-44\end{array}$ & & 8.6 & $\begin{array}{l}\text { Referent } \\
1.77\end{array}$ & $1.54-2.04$ \\
\hline $\begin{array}{l}35-44 \\
45-54\end{array}$ & $\begin{array}{l}4265 \\
2854\end{array}$ & 14.4 & $\begin{array}{l}1.77 \\
1.94\end{array}$ & $\begin{array}{l}1.54-2.04 \\
1.67-2.26\end{array}$ \\
\hline $\begin{array}{l}45-54 \\
55-64\end{array}$ & 1573 & $\begin{array}{l}16.5 \\
15.3\end{array}$ & $\begin{array}{l}1.94 \\
1.84\end{array}$ & $1.50-2.27$ \\
\hline \multicolumn{5}{|l|}{$\begin{array}{l}55-64 \\
\text { Race/ethnicity }\end{array}$} \\
\hline $\begin{array}{l}\text { White } \\
\text { Black }\end{array}$ & 9835 & 14.8 & Referent & \\
\hline $\begin{array}{l}\text { Black } \\
\text { Asian }\end{array}$ & 1411 & 6.9 & 0.44 & $0.35-0.54$ \\
\hline $\begin{array}{l}\text { Asian } \\
\text { American Indian }\end{array}$ & 271 & 6.4 & 0.50 & $0.30-0.81$ \\
\hline $\begin{array}{l}\text { American Indian } \\
\text { Hispanic }\end{array}$ & 241 & 10.9 & 0.85 & $0.55-1.31$ \\
\hline $\begin{array}{l}\text { Hispanic } \\
\text { Other }\end{array}$ & 1243 & 8.3 & 0.64 & $0.50-0.82$ \\
\hline $\begin{array}{l}\text { Other } \\
\text { Gross income in } 199\end{array}$ & 29 & 2.5 & 0.20 & $0.02-2.39$ \\
\hline \multicolumn{5}{|c|}{$\begin{array}{l}\text { Other } \\
\text { Gross income in } 1993 \text { (US\$) }\end{array}$} \\
\hline $\begin{array}{l}<\$ 10000 \\
\$ 10000-\$ 25000\end{array}$ & 1319 & 8.5 & $\begin{array}{l}\text { Referent } \\
1.03\end{array}$ & \\
\hline $\begin{array}{l}\$ 10000-\$ 25000 \\
\$ 25001-\$ 40000\end{array}$ & 3205 & 8.5 & 1.03 & $0.80-1.32$ \\
\hline $\begin{array}{l}\$ 25001-\$ 40000 \\
>\$ 40000\end{array}$ & 3655 & 12.4 & 1.48 & $1.16-1.88$ \\
\hline $\begin{array}{l}>\$ 40000 \\
\text { Education (years) }\end{array}$ & 4093 & 18.1 & 2.19 & $1.72-2.79$ \\
\hline $\begin{array}{l}<12 \\
12\end{array}$ & $\begin{array}{l}1944 \\
2486\end{array}$ & 10.1 & $\begin{array}{l}\text { Rererent } \\
0.93\end{array}$ & \\
\hline $\begin{array}{l}12 \\
13-15\end{array}$ & $\begin{array}{l}2486 \\
6159\end{array}$ & 11.7 & 1.13 & $\begin{array}{l}0.75-1.15 \\
0.93-1.37\end{array}$ \\
\hline $\begin{array}{l}13-15 \\
\geqslant 16\end{array}$ & $\begin{array}{l}6159 \\
2469\end{array}$ & 14.2 & 0.92 & $\begin{array}{l}0.93-1.31 \\
0.74-1.15\end{array}$ \\
\hline \multicolumn{5}{|l|}{$\begin{array}{l}\geqslant 16 \\
\text { Employment status }\end{array}$} \\
\hline Employed & 9452 & 13.2 & Referent & \\
\hline Retired & 707 & 16.3 & 1.20 & $0.92-1.56$ \\
\hline Student & 396 & 10.6 & 1.20 & $0.85-1.70$ \\
\hline Homemaker & 1026 & 13.7 & 0.96 & $0.77-1.19$ \\
\hline Unemployed & 1343 & 10.0 & 0.99 & $0.80-1.23$ \\
\hline
\end{tabular}

$\mathrm{CI}=$ confidence intervals. regression analysis was conducted to model use of the patch among cohort participants with the variables noted above along with an indicator variable to control for any effect of the COMMIT intervention. The SPSS statistical software package was used to conduct all analyses. ${ }^{21}$

Data from the cross-sectional survey and cohort tracking survey were used to investigate the relationship between public insurance coverage of the nicotine patch and use of the patch. Weighted percentages of patch use were obtained from the cross-sectional survey for different income categories stratified by whether or not the individual lived in a state that did or did not cover the nicotine patch in its public insurance programme. In addition, separate logistic regression analyses were performed to estimate the effect of public insurance coverage of the patch on patch use for respondents earning low incomes (household income $<\$ 10000$ annually) and those with higher incomes (household income $>\$ 10000$ ), controlling for sociodemographic variables (gender, age, race/ethnicity, education, employment status) and the COMMIT intervention. A similar analysis was performed using the data from the cohort tracking survey, except that the logistic regression analyses included a more comprehensive list of control variables (baseline measures of tobacco use behaviour and indicators of motivation to stop smoking).

Data from the cohort tracking survey were used to evaluate the use of the nicotine skin patch as a means for stopping smoking. Logistic regression analyses were performed to model the smoking status of cohort participants assessed in 1993 (smoker or quitter) as a function of use of the nicotine skin patch while controlling for sociodemographic variables, baseline measures of tobacco use behaviour, indicators of motivation to stop smoking, and exposure to the COMMIT intervention. Two measures of nicotine patch use were examined in these analyses: (a) use vs no use of the patch; and (b) duration of patch use $(0,1-7,8-28,29-90,>90$ days).

\section{Results}

USE OF THE NICOTINE PATCH AND OTHER

SMOKING CESSATION METHODS

The reported use of the transdermal nicotine skin patch from the 1993 cross-sectional survey was $12.8 \%$ (range $8.2-14.9 \%$ ), 95\% confidence interval $(\mathrm{CI})=12.2 \%$ to $13.4 \%$. Among those who reported using the patch, the median number of days of use was 15 with a wide distribution of the number of days wearing it. Five per cent of patch users reported wearing it for one day or less, $26 \%$ used it between two and seven days, $29 \%$ used it between eight and 28 days, $36 \%$ used it between 29 and 90 days, $2 \%$ reported wearing the patch over 90 days, and $2 \%$ could not recall how many days they had used the patch (data not shown).

To gauge the popularity of the transdermal nicotine patch relative to other smoking cessation methods, we also estimated the use of 


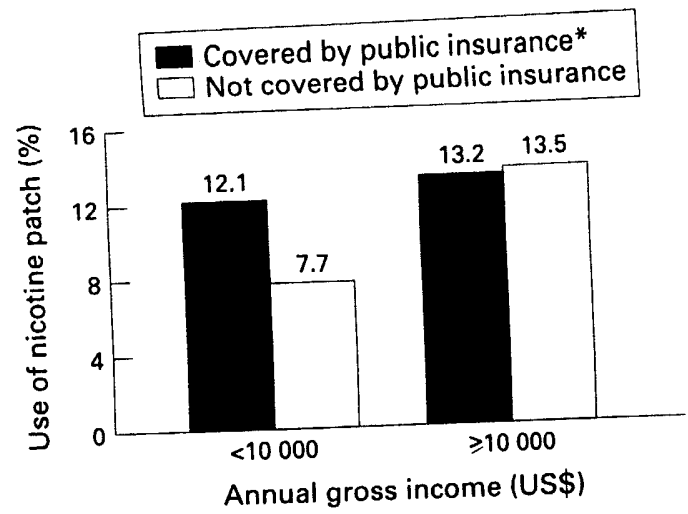

Figure 1 Use of the nicotine skin patch by income and public insurance coverage from the cross-sectional survey. * Adjusted $O R=2.19$ and 0.95 for the $<U S \$ 10000$ and $\geqslant$ US 10000 groups respectively from the cohort dataset.

Table 3 Characteristics associated with use of the nicotine skin patch from the cohort tracking survey

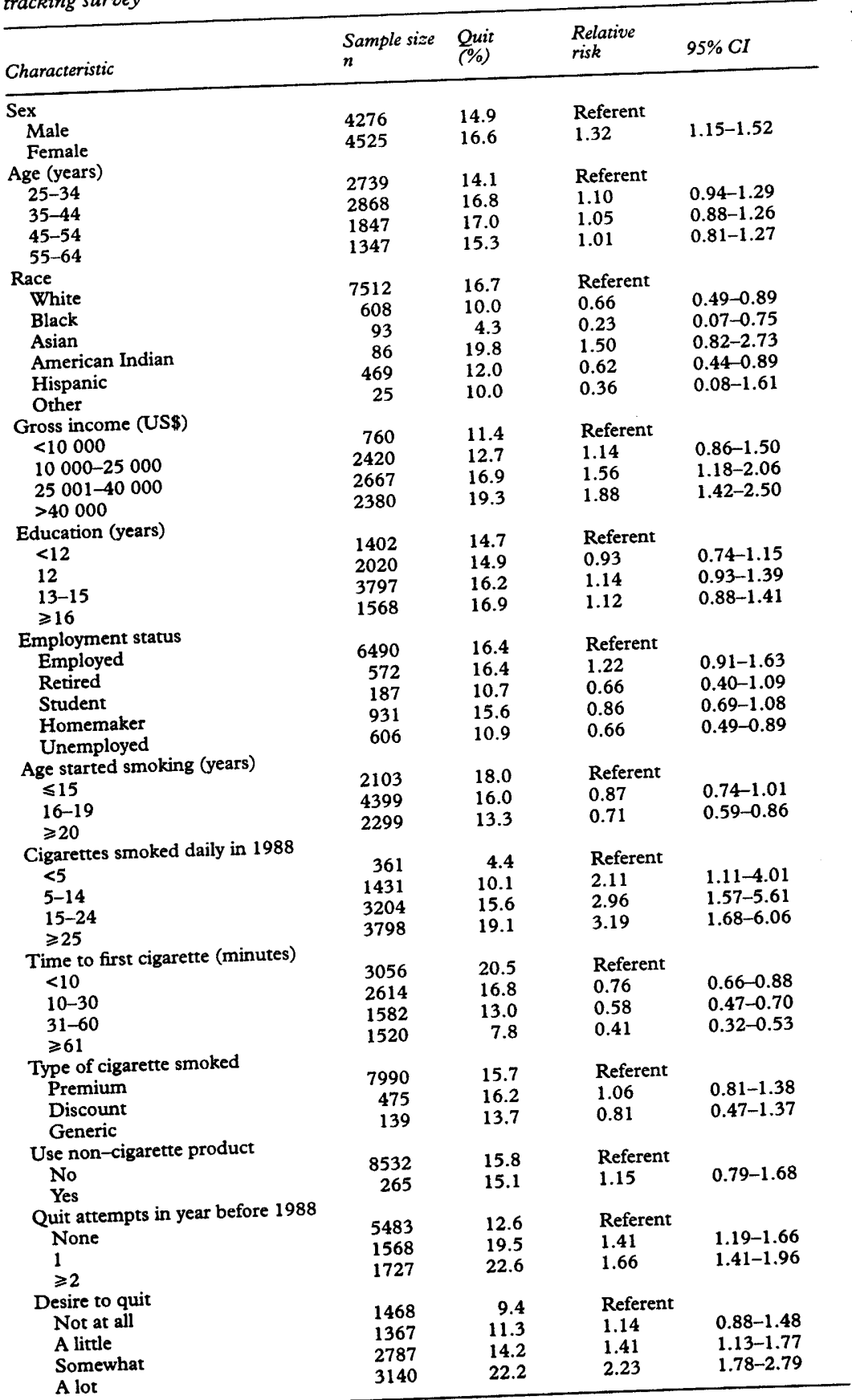

other methods reported by current and former smokers. Table 1 shows the use of the nicotine skin patch compared with the use of the following methods reported over a five-year period between 1988 and 1993.

- Nicotine gum

- Decrease consumption

- Switch to low tar cigarettes

- Attendance at a smoking cessation clinic

- A visit to a hypnotist or acupuncturist

- Counselling from a psychiatrist or psychologist

- Advice from physician

- Use of self-help books or guides

- Use of commercial devices such as special filters.

Despite the fact that the patch had only been available to smokers for a two-year period (1992 and 1993), it was among the most commonly reported methods used by smokers to quit. The most frequently mentioned methods used to stop smoking were quitting "cold turkey" $(68 \%)$, gradually decreasing cigarette consumption (45\%), and switching to lower tar and lower nicotine cigarettes $(30 \%)$. Fewer than one in five nicotine patch users reported attending a smoking cessation programme $(18 \%)$, whereas over half reported using self-help books or guides (57\%). Unfortunately, it is not apparent from the way questions were asked in the survey whether or not the use of other smoking cessation methods were done separately or in conjunction with the use of the nicotine patch.

\section{CHARACTERISTICS OF PATCH USERS}

Table 2 shows the distribution of sociodemographic characteristics associated with patch use estimated from the 1993 cross-sectional survey, together with adjusted risk ratios from the logistic regression analysis. Women were approximately $43 \%$ more likely to be patch users than men. Patch use was about twice as likely among those aged over 35, compared with those under 35 . Compared with white smokers, only about half as many Hispanic or black smokers used the patch. Household income was related to the use of the patch with those individuals reporting a 1993 gross household income of more than $\$ 400002.19$ times more likely to be patch users compared with those with incomes under $\$ 10000(95 \%$ $\mathrm{CI}=1.72$ to 2.79 ).

In the cohort tracking group, $15.8 \%$ of smokers reported using the transdermal nicotine patch. As shown in table 3, the pattern of the relationship of sociodemographic variables to patch use for the cohort are similar to the pattern for the cross-sectional group, that is, higher use among women, whites, and higher income groups. The one exception was age, which was not a significant predictor of patch use among cohort participants. The cohort tracking survey allowed us to examine baseline measures of tobacco use behaviour and indicators of motivation to stop smoking as predictors of nicotine patch use. Patch use was more prevalent among individuals who smoked heavily, smoked within 30 minutes after awakening, reported a strong desire to 
Table 4 Results of logistic regression modelling smoking cessation by duration of nicotint skin patch use from the cohort tracking survey

\begin{tabular}{lrrrr}
\hline & \multicolumn{3}{c}{ Sample size } & Relative \\
\cline { 2 - 4 } Days using the patch & $n$ & $\%$ & Referent & $95 \%$ CI \\
\hline Non-user & 7415 & 84.4 & 1.10 & $0.70-1.74$ \\
$1-7$ & 377 & 4.3 & 2.18 & $1.54-3.10$ \\
$8-28$ & 396 & 4.5 & 4.65 & $3.64-5.95$ \\
$29-90$ & 563 & 6.4 & 2.86 & $1.06-7.67$ \\
$\geqslant 91$ & 35 & 0.4 & & \\
\hline
\end{tabular}

*Risk estimates are adjusted for the following variables: gender, age, income, education, amoun smoked daily in 1988, age started smoking, time to first cigarette, type of cigarette smoked in 1988, use of non-cigarette tobacco products in smoking, COMMIT intervention.

$\mathrm{desire}$ to stop smoking, $\mathrm{CI}$ = confidence intervals.

stop smoking, and indicated that they had made one or more quit attempts in the year before enrolling in the cohort in 1988 .

PUBLIC INSURANCE COVERAGE AND PATCH USE Between 1992 and 1993, five of the nine states (California, New Jersey, New Mexico, North Carolina, Oregon) provided coverage for transdermal nicotine patch under their public health insurance programme, whereas the other four states (Iowa, Massachusetts, New York, Washington) did not provide any coverage. In California, coverage of the nicotine patch required patients to provide evidence that they were concurrently participating in a smoking cessation programme. In Oregon, coverage of the nicotine patch required that the patient be diagnosed as nicotine dependent, make a commitment to quit smoking within 30 days of their diagnosis, and receive the pharmaceutical manufacturer's product self-help kit, or handouts, or both, along with their prescription. North Carolina required their Medicaid patients to pay a $\$ 1$ co-payment per prescription. There were no special restrictions on Medicaid coverage for the nicotine patch in New Jersey and New Mexico.

Figure 1 shows the percentage of current and former smokers from the 1993 cross-sectional survey who reported using the patch by income level in states that did and did not have public insurance coverage for the patch. These rates are adjusted to the racial distribution in the 1993 cross-sectional prevalence survey to take into account the wide variation in patch use by race/ethnicity and the differences by race/ethnicity by community. Overall, the percentage using the patch increased with income level. For individuals who reported an annual household income of $\$ 10000$ or more, patch use was about the same between those who lived in states with or without public insurance coverage for the patch $(13.2 \%$ with coverage vs $13.5 \%$ with no coverage). However, among those individuals with annual incomes below $\$ 10000$, patch use was $57 \%$ higher if the state public insurance programme covered it, compared with those individuals from states where the patch was not a covered benefit $(12.1 \%$ with coverage vs $7.7 \%$ without coverage). This result holds even after adjustment for sociodemographic factors.

We also investigated the effect of public insurance coverage on the use of the nicotine patch using data collected from the cohort tracking survey. The findings were essentially the same as those obtained using data from the 1993 cross-sectional survey. Adjusted for sociodemographic variables, measures of past and current tobacco use, and indicators of motivation to stop smoking, reported patch use among low income cohort participants was 2.19 times more likely $(95 \% \mathrm{CI}=1.28$ to 3.73 ) in those individuals from states whose public insurance programmes covered the patch compared with those individuals who lived in states where it was not covered. Among cohort participants whose annual household incomes were $\$ 10000$ and higher, use of the patch was nearly identical between those individuals who lived in states that did and did not cover the patch (relative risk $=0.95,95 \% \mathrm{CI}=0.83$ to 1.08).

\section{NICOTINE PATCH AS AN AID IN QUITTING} SMOKING

Logistic regression was used to model quitting behaviour as a function of nicotine patch use and known correlates of smoking cessation. ${ }^{14-16}{ }^{18}$ (See Hymowitz et al, page S57 of this supplement) among cohort participants who reported making at least one attempt to stop smoking since January 1992. Adjusted for sociodemographic variables, baseline measures of tobacco use (amount smoked daily, time to first cigarette, age started smoking), and indicators of motivation to stop smoking (desire to quit smoking, reported past quit attempts), use of the nicotine patch was associated with a 2.74 times greater likelihood of quitting smoking ( $95 \% \mathrm{CI}=2.25$ to 3.35 ) compared with not using the patch. Use of the patch was associated with a higher likelihood of quitting even among moderate and light smokers ( $<20$ cigarettes/day), although the differential in quit rates between patch users and nonusers was greatest among heavier smokers $(\geqslant 20$ cigarettes/day: quit rate among patch users $=13 \%$ vs $5 \%$ among non-users; $<10$ cigarettes/day: quit rate among patch users $15 \%$ vs $10 \%$ among non-users). Low income smokers who used the patch were as successful as higher income smokers (odds ratios $=2.60$ and 2.75 respectively).

Duration of patch use up to 90 days was associated in a dose-dependent manner with an increased likelihood of quitting smoking (table 4). After 90 days, use of the patch was associated with a significantly higher quit rate compared with no use of the patch, but lower compared with those using the patch for one to three months. There was no significant interaction between amount smoked and use of the patch on successful smoking cessation. Other than the transdermal nicotine patch, no other method or device for quitting smoking was significantly associated with success in stopping smoking.

\section{Discussion}

This is one of the few studies to have examined the use and effectiveness of the nicotine patch outside a specialised smoking cessation clinic or controlled clinical trial. Therefore, the 
major study findings are likely to be a better representation of the prevalence of patch use, who is actually using it, and its effectiveness in the general population than those provided in other studies.

The following are the three main findings from this study: (a) between 1992 and 1993, the transdermal nicotine patch was among the most popular methods used by smokers to try to stop smoking; (b) patch use was associated with approximately a doubling of the likelihood of quitting smoking; and (c) use of the patch was strongly related to income; among those with annual household incomes below $\$ 10000$, patch use was significantly higher in states where public health insurance covered it. These findings are consistent with the published research on the efficacy of the nicotine skin patch, which shows that use of the patch approximately doubles 6-12-month abstinence rates over those produced by placebo interventions. ${ }^{39-11}$

Unfortunately, because the COMMIT study was not intended to be a study of nicotine replacement therapy, there are several issues about how the patch was used by smokers for which information was not gathered, such as whether they smoked while using the patch, dosing patterns, and the use of adjuvant therapies. However, a previous study by Cummings and colleagues ${ }^{21}$ of 284 adult smokers who had received a prescription for the nicotine patch in 1992 found that only nine ( $3 \%$ ) had attended a smoking cessation programme while using the patch, most reported getting proper advice from their physician on how to use the patch, and most were compliant with the patch regimen. Side effects associated with the patch were common, but did not cause many patients to discontinue therapy. Most patients, including those who relapsed back to smoking, rated the nicotine patch as either "very" or "somewhat" helpful in their effort to stop smoking.

Despite the fact that the nicotine patch had only been available for under two years at the time of our survey, approximately one of eight smokers reported having used it. By comparison, over a five-year period (1988 to 1993), only one of 10 smokers reported using nicotine gum, one of 13 had attended a smoking cessation programme, one of 16 had gone to a hypnotist or acupuncturist, and one of 20 had used some other commercially available device. Moreover, use of the nicotine patch was the only one of these methods associated with a significantly higher quit rate. This result is even more remarkable when one considers the fact that patch users smoked more heavily compared with non-users. The extensive amount of advertising by the pharmaceutical industry to promote different nicotine patch brands in 1992 and 1993 combined with its greater effectiveness for smoking cessation probably accounts for its greater popularity among smokers in our study compared with other smoking cessation methods.

For many years, public health officials have been calling for greater availability of smoking cessation programmes. ${ }^{32}{ }^{23}$ Research has dem- onstrated that success rates for smoking cessation increase in relation to the intensity of the treatment provided and the number of treatment components used to intervene. ${ }^{34}$ For example, several studies have shown that smokers are more likely to be successful in quitting if nicotine replacement therapy is combined with a behavioural support programme. ${ }^{141524}$ Unfortunately, surveys show that only a small percentage of smokers use organised smoking cessation programmes, and lower income smokers in particular are less likely to make use of such programmes. ${ }^{152123}$ Operating under the assumption that better financing of treatments for tobacco dependence would expand access and lead to higher smoking cessation rates, many policy experts have recommended that insurance coverage be increased for smoking cessation therapies. ${ }^{326}$ For example, the Agency for Health Care Policy and Research recommends that counselling and pharmacotherapy for smoking cessation treatments be provided as paid services for subscribers of health insurance/ managed care organisations. ${ }^{3}$ The American Society of Addiction Medicine similarly recommends that third-party payers make coverage for the treatment of nicotine dependence available to all group and individual enrollees. ${ }^{26}$ Despite these recommendations, and clear evidence regarding the efficacy of the transdermal nicotine patch as a treatment for tobacco dependence, many third-party payers have been reluctant to provide coverage and easy access to this treatment, as indicated by the fact that in 1994 only 23 of 50 states reported public insurance coverage for nicotine replacement products (nicotine gum, patches, or both) (Pinney Associates, unpublished manuscript).

In a study of public insurance agencies that examined reasons for not covering smoking cessation services, the most common reasons given included a perception that smoking cessation treatments are readily available to those who want them at a low cost; a view that smoking cessation is not a "medical service" and thus not eligible for coverage; and concerns about the effectiveness of smoking cessation treatments. ${ }^{5}$ Even among insurers who provide coverage for the patch, many have implemented procedures that make it difficult for smokers to gain access to it. For example, some managed-care organisations will only reimburse for a nicotine patch prescription if the smoker is also enrolled in a smoking cessation programme. Although the combination of nicotine replacement therapy with a behavioural support programme is a good idea, practically speaking, for many smokers enrolment in a programme may entail a time commitment that is not feasible or acceptable. Several studies have demonstrated that smokers do not like to attend groups and very small percentages actually do so. ${ }^{21} 23$

Consistent with other studies on the use of the patch, our results show that use of the nicotine patch is inversely related to income level (higher income is associated with higher use)..$^{14}$ Moreover, among the poor, public 
insurance coverage of the patch was associated with greater use of the patch and higher quit rates. This result suggests that lack of ability to pay for the patch, or the need for a prescription which requires having access to healthcare, or both, may represent a significant barrier to its use among the poor. It is our opinion that medical insurance coverage probably increases use of the nicotine patch as well as other types of smoking cessation treatments in all income groups. However, this statement should be viewed cautiously as we did not directly measure insurance coverage of the nicotine patch among smokers in our study and thus could not test this hypothesis. In addition, it is not at all clear from this study how different coverage options-for example, co-payment or required enrolment in a smoking cessation programme-might affect use.

In an effort to increase access to nicotine replacement therapies for smoking cessation, the FDA recently approved the over-thecounter (OTC) sale of nicotine gum (Nicorette) and nicotine patches (Nicotrol and Nicoderm). Although it is still too early to judge the impact of OTC availability on the use of the nicotine patch, it is presumed that access will be increased as smokers will be able to get the patch when they are ready to use it without the typical delays associated with physician visits and infrequently scheduled cessation programmes. On the other hand, OTC status may reduce access by increasing the out-of-pocket cost of the patch for smokers as medical insurance companies are not likely to cover the patch OTC. ${ }^{7}$ (Pinney Associates, unpublished manuscript). An informal survey conducted in July 1996 of pharmacies in the Buffalo area found that the cost of a starter kit for the nicotine patch (with seven patches in the kit) ranged from $\$ 25$ to $\$ 35$. For many smokers the high initial price of the patch may deter use, especially when compared with the typical cost of about $\$ 2.25$ for a package of cigarettes. In addition, FDA regulations that restrict the sale of OTC nicotine patches and gum to drug stores may limit access to these products, especially in low income communities where pharmacies are less abundant.

To further increase the availability and use of the nicotine skin patch the following recommendations are offered. (a) Medical insurance providers should be encouraged through the use of incentives and quality assurance standards to offer smokers incentives (copayment, discounts) to use the nicotine patch to help them quit smoking. (b) The FDA should ease its restrictions on the types of retail outlets where the nicotine skin patch and nicotine gum can be sold (that is, include small food and convenience stores). (c) The FDA regulations on packaging of nicotine patches and gum should be reconsidered to allow drug manufacturers to experiment with selling smaller units at a lower cost to consumers. It is not logical that nicotine skin patches and gum that can help a smoker break his/her dependence on tobacco products are less accessible and more costly to purchase than is a pack of cigarettes.

Support for this research has been provided by the National Support for this rest Wood Johnson Foundation. W Cancer Institute and colleagues at the 11 COMMIT research are indebted to our colleagues at center, Information Managesites, the COMMIT coordinating center, ment Services, Inc., and staff at the National Cancer Instion who planned and coordinated

1 Cummings SR, Rubin SM, Oster G. The cost-effectiveness

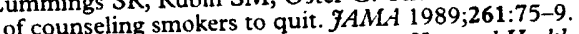
of counseling smokers to quit. Eddy DM. David Eddy ranks the tests.

ter 1992 Jul special supplement:10-11. Smoking cessation. Clinical Practice Guideline No 18. Rockville, Maryland: US Department of Health and Human Services, Public Health Service, Agency for Health Care Policy and Health Service, Agency (AHCPR Publication No 96-0692.) Research, April 1996. Ar HH, Kottke TE, et al. Report of Parkinson $M D$, Schauffier $\mathrm{HF}$, Kotcke the tobacco policy research study group on reimbursement; and insurance in

1(suppl):S52-56. Schauffer HH, Parkinson $M$. Health insurance coverage smoking cessation. Health Educ $Q$ 1993;20:185-206.

6 Schauffler HH, Gentry D. Smoking control policies in private insurance in California: result

Pinney JM. Review of the current status of smoking

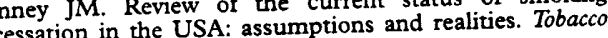
Control 1995;4(suppl):S10-14.

8 Warner KE. Policy issues. Issues in smoking cessation-who quits? Who pays? Tobacco Control 1993;2(suppl):S79-83.

quits? Whacco Fiore MC, Sorenby DE, Baker TB, Kenford dependence and the nicotine patch. Clinica 10 Tang JL, Law $M$, Wald $N$. How effective is nicotine replacement therapy in
$1994 ; 308: 21-6$.

11 Silag C, Mont D, Fowler G, Lodge M. Meta-analysis on Silagy $C$, Mont $D$, Fowler $G$, Lod therapies in smoking cesefficacy of nicotine replacement

12 Glaser M. Nicotine patches lead $R$. activity to new heights. Drug Topics 1993;137:72-8.

13 COMMTT Research Group. Community interventiona trial for smoking cessation (COMMIT): summary of desig for smoking cessation

14 Pierce JP, Gilpin E, Farkas AJ. Nicotine patch use in the general population: results from the 1993 Califc Tobacco Survey. F Natl Cancer Inst 1995;87:87-93.

15 Orleans CT, Resch N, Neil E, et al. Use of transdermal nicotine in a state-level prescription plan for the elderly. A firs. look at 'real world' patch users. FAMA 1994;271:601-7.

16 Haxby D, Sinclair A, Eiff MP, et al. Characteristics and perceptions of $\mathrm{n}$.
38(5):459-64.

17 Mattson ME, Cummings KM, Lynn WR, et al. Evaluation plan for the community intervention trial for smoking cesplation (COMMIT). Int $Q$ Commun Health Educ 1991; 11:271-90.

18 COMMIT Research Group. Community Intervention Trial for Smoking Cessation (COMMIT). I. Cohort results Health 1995;85:183-92.

19 COMMIT Research Group. Community Intervention Trial for Smoking Cessation (COMMIT). II. Changes in adult cigarette smoking prevalence. Am 7 Public Health 1995; 85:193-200.

20 Norusis MJ. SPSS For Windows: advanced statistics, release 6.0. SPSS, 1993.

21 Cummings KM, Biernbaum RM, Zevon MA, et al. Use and effectiveness of transdermal nicotine in primary care settings. Arch Fam Med 1994;3:682-9.

22 US Department of Health and Human Services. The health consequences of smoking: nicotine addiction. A report of the consequences of smoking: nicotine addiction. A report of the Surgeon General, 1988. Rockville, Maryland. Public Health Service, Centers for Disease Control, Office No (CDC) 88-8406.)

23 Fiore MC, Novotny TE, Pierce JP, et al. Methods used to quit smoking in the United States. $f A M A 1990 ; 263: 2760$

24 Kottke TE, Battista RN, DeFriese GH, Brekke ML. Atrributes of successful smoking cessation interventions in medical practice: a meta-analysis of 39 controlled trials. ҰAMA 1988;259:2882-9.

25 Foulds J. Stapleton J, Hayward M, et al. Transdermal nicotine patches with low-intensity support to aid smoking cessation in outpatients in a general hospital. Arch Fam Med 1993;2:417-23.

26 American Society of Addiction Medicine. Public policy statement on reimbursement for treatment of nicotine dependence. Chevy Chase, Maryland: Ame 